\title{
An Evaluation of Contractility Parameters Determined from Isometric Contractions and Micturition Studies
}

\author{
R. van Mastrigt and D. J. Griffiths \\ Departments of Urology and Biological and Medical Physics, Erasmus University, Rotterdam, The Netherlands
}

Accepted: July 19, 1985

Summary. In a group of 110 patients of mixed pathology 218 micturitions were investigated. Using an on-line computer, two contractility parameters were calculated: the parameter $\mathrm{U} / \mathrm{l}$, which is derived from the isometric pressure rise in the detrusor before micturition actually started, and the parameter $\mathrm{w}_{\max }$, which is derived from flow and pressure during micturition. It was found that neither of the parameters conforms to the definition of an ideal contractility parameter. Both parameters are subject to the influence of the urethral resistance or the degree of neurogenic stimulation of the bladder, and both measure to some degree the actual performance of the detrusor during a given micturition instead of its myogenic properties. Nevertheless, by dividing patients into groups according to these two measured values, it was shown that clinically relevant types of detrusor behaviour can be distinguished.

Key words: Phase plot, Urinary bladder, Bladder, Bladder power, Myogenic properties, Pressure-flow study.

\section{Introduction}

The act of micturition is the result of an interaction between local or central neurogenic control mechanisms and a mechanical system consisting of bladder and urethra, as depicted in Fig. 1. In generating the energy necessary for micturition, the urinary bladder is subject to certain intrinsic mechanical limitations which are covered by the concept of contractility. A poor micturition, for instance one with residual urine, might be due to a failure in any of the three parts of the system shown in Fig. 1. It might be due to the neurogenic control (e.g. dyssynergia), to the urethra (e.g. anatomical obstruction) or to the bladder (e.g. overstretching). Since different methods of treatment may be indicated for different types of failure, it is important to be able to

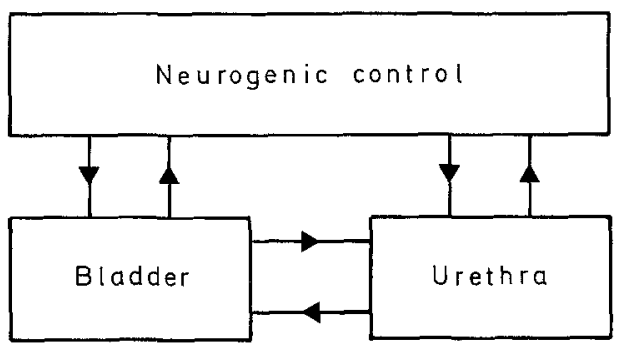

Fig. 1. Functionally different systems involved in micturition

discriminate between them. A method of determining the contractility of the bladder provides such a possibility. Contractility parameters can be calculated from isometric contractions, such as the pressure rise in the bladder immediately preceding micturition, from measurements of pressure and flow during micturition, and/or from a manipulated micturition.

From an isometric contraction a relation between contraction force and shortening velocity can be calculated, which is the basic, physiological relationship defining contractility [6]. This method can only be applied to a very limited number of patients as it is very sensitive to the influence of neurogenic control [8]. A second method of calculating a contractility parameter from isometric contractions by making phase plots [15] can be applied to almost all patients [9]. It yields a parameter which is correlated with the maximum contraction velocity [10].

From measurements of pressure and flow during micturition a relation between bladder pressure and bladder contraction velocity can be calculated which resembles the force-velocity relation. For a very limited class of patients such a curve approximates a theoretical curve so that contractility parameters can be estimated from it [14]. For almost all patients the curve can be used to evaluate bladder contractility on a three point scale [4]. By calculata new variable, an approximate "micturition power", from the curves however, the effort of the bladder during the 

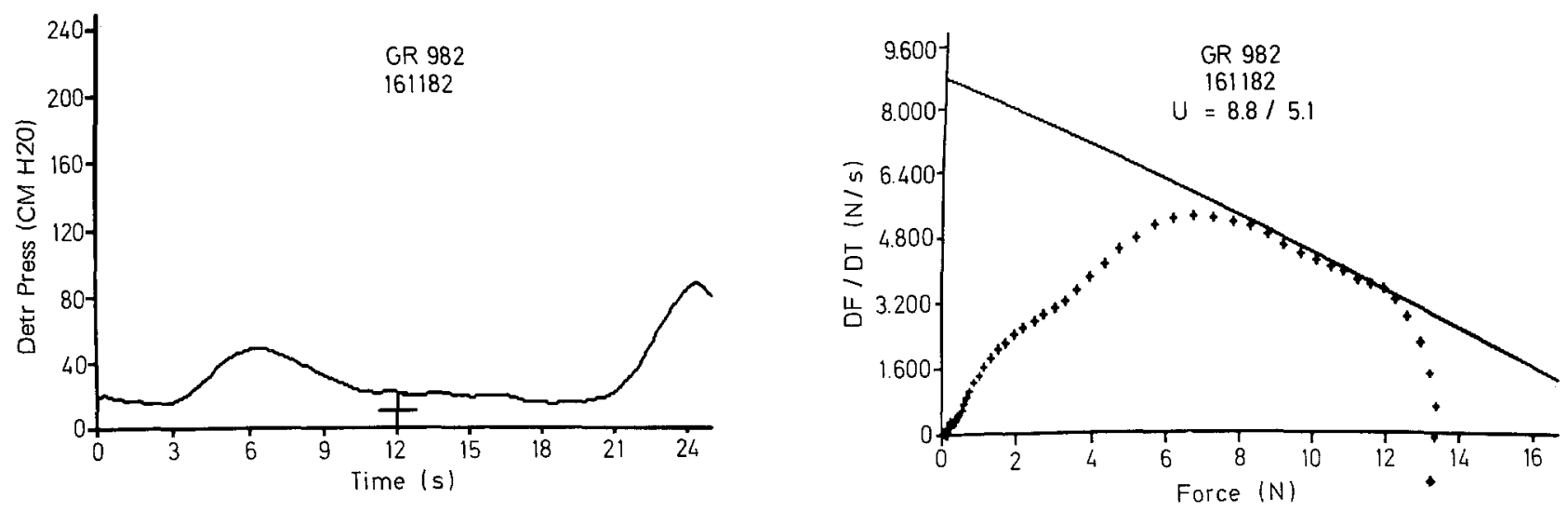

Fig. 2. Pressure as a function of time during an isometric contraction immediately preceding micturition

Fig. 3. Phase plot calculated from the data of Fig. 2. Rate of rise of bladder force as a function of the force itself. Straight line was "fitted" to the data without altering the slope of the line. Intersection of this line with the vertical axis forms the parameter $\mathrm{U}$

entire act of micturition can be plotted and evaluated using a continuous scale [16].

Examples of methods for determining contractility parameters from manipulated micturitions are the "stoptest" [1], and an adaptation of the quick-release technique well known in muscle physiology [17]. Both are attractive from a theoretical point of view but complicated in clinical practice, and also may possibly lead to unforeseen interactions with the neurogenic control of the system. These methods will not be discussed in this study.

The contractility parameter determined from phase plots of isometric contractions and the power parameter determined from micturition studies were shown to be correlated in patients [11]. This indicates that both parameters reflect to some extent the same properties, hopefully the "contractility" of the bladder defined above. Since however the correlation is not very strong, they do not yield identical information, and for some patients the information appears to be conflicting [14]. This study aims to evaluate the two types of parameters, by answering the following questions:

1. Do these parameters measure the contractility of the bladder?

2. If so, how can apparently conflicting values of the two parameters be interpreted?

\section{Material and Methods}

A group of 110 patients of mixed pathology was subjected to our standard urodynamic procedures. The group consisted of 49 children and 61 adults. The children were catheterized with a $3.5 \mathrm{~F}$ waterfilled catheter with attached pressure transducer and an $8 \mathrm{~F}$ filling catheter. Three successive cycles of medium fill cystometry followed by voiding were measured. Before the last voiding the filling catheter was removed [2]. The adults were catheterized with two $5 \mathrm{~F}$ catheters and in general two successive studies were performed. In both cases the urodynamic apparatus was directly connected to a remote minicomputer, and pressure and flow during micturition together with the (isometric) pressure rise just before micturition started were stored on disc and processed immediately following each measurement $[7,13,12]$.

Figure 2 shows an example of a measured isometric pressure rise exactly as presented on the graphics screen in the cystometry room immediately following the actual measurement. From these data a phase plot was calculated (Fig. 3, again similar to the on-line presentation) which is a plot of the rate of rise of force in the bladder wall as a function of the force itself. This force was calculated from detrusor pressure and volume as the total force acting around the circumference of the bladder [5]. Since studies in vitro have demonstrated that the phase plot of an ideal isometric contraction shows a straight line part with a fixed slope [15], such a line, with preset slope, was "fitted" to the clinical data, even if no straight line part was recognizable. The intersection of this line with the vertical axis, which is an extrapolated maximum rate of force rise, is the parameter $U$, which was shown to be correlated with the maximum velocity of contraction of bladder strips in vitro [10]. As the parameter $U$ is proportional to the initial length of bladder strips, it was in the clinical case divided by the bladder circumference, as calculated from the bladder volume assuming a spherical bladder, and the quotient was denoted by $\mathrm{U} / 1$.

For each micturition study, a plot of velocity of contraction of the urinary bladder wall as a function of detrusor pressure was made (Fig. 4.). Contraction velocity was obtained by calculating from the flow signal first the volume in the bladder, then the circumference of the bladder, assuming it to be spherical, and finally the rate of change of this circumference. From the contraction velocity and the pressure a variable $w$, which approximates the power generated by the bladder per surface area, was calculated [16] and plotted as a function of time (Fig. 5). This variable approximately represents one curve out of a set of parallel, theoretical contraction velocity versus pressure curves. The maximum value reached during micturition, represents the velocity/pressure curve lying at the greatest distance from the origin, thus the "contractility" of the detrusor.

From each filling-voiding cycle we obtained a value for the parameter $U / 1$, calculated from the premicturition contraction, and a value for $w_{\max }$, calculated from the voiding. Following each cycle, residual urine was determined. In total 218 successful measurements were made on the 110 patients. For each patient the measured parameters and the residual urine were averaged and the contractility of the bladder was classified as high or low by comparing the average value of a contractility parameter with its overall median value, thus yielding in total four patient classes using both parameters. For each class the average residual urine and bladder volume were calculated. 

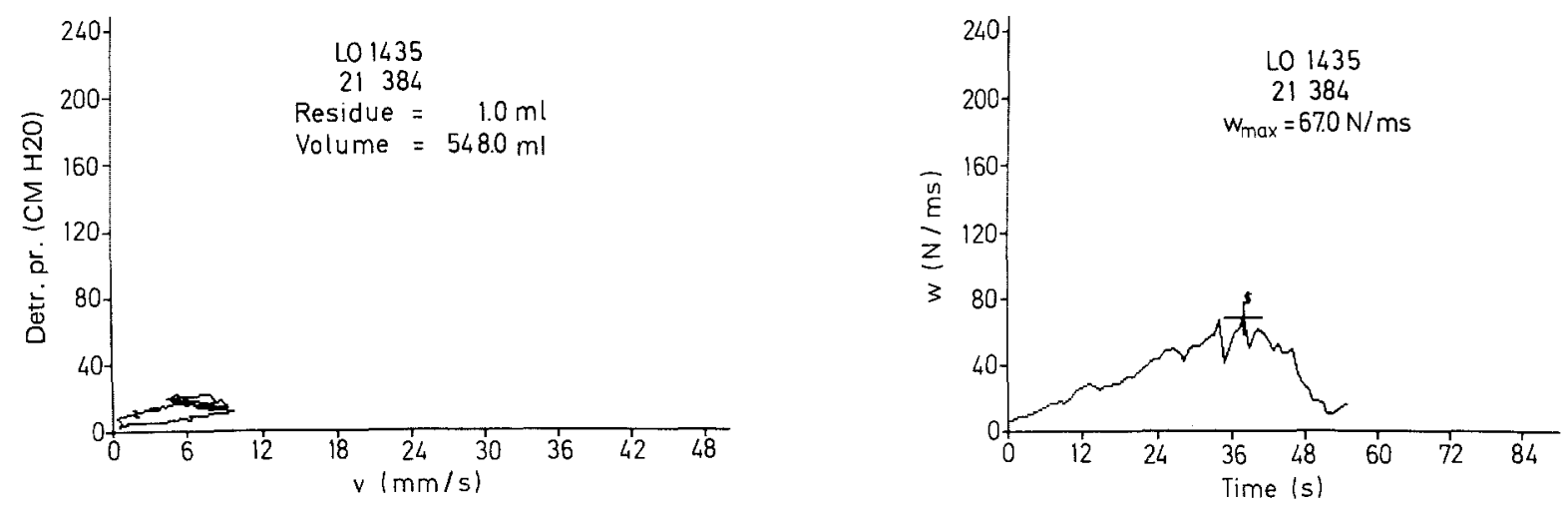

Fig. 4. Contraction velocity of the urinary bladder as a function of detrusor pressure, calculated from a measurement of pressure and flow during micturition

Fig. 5. The parameter w, calculated from Fig. 4, as a function of time
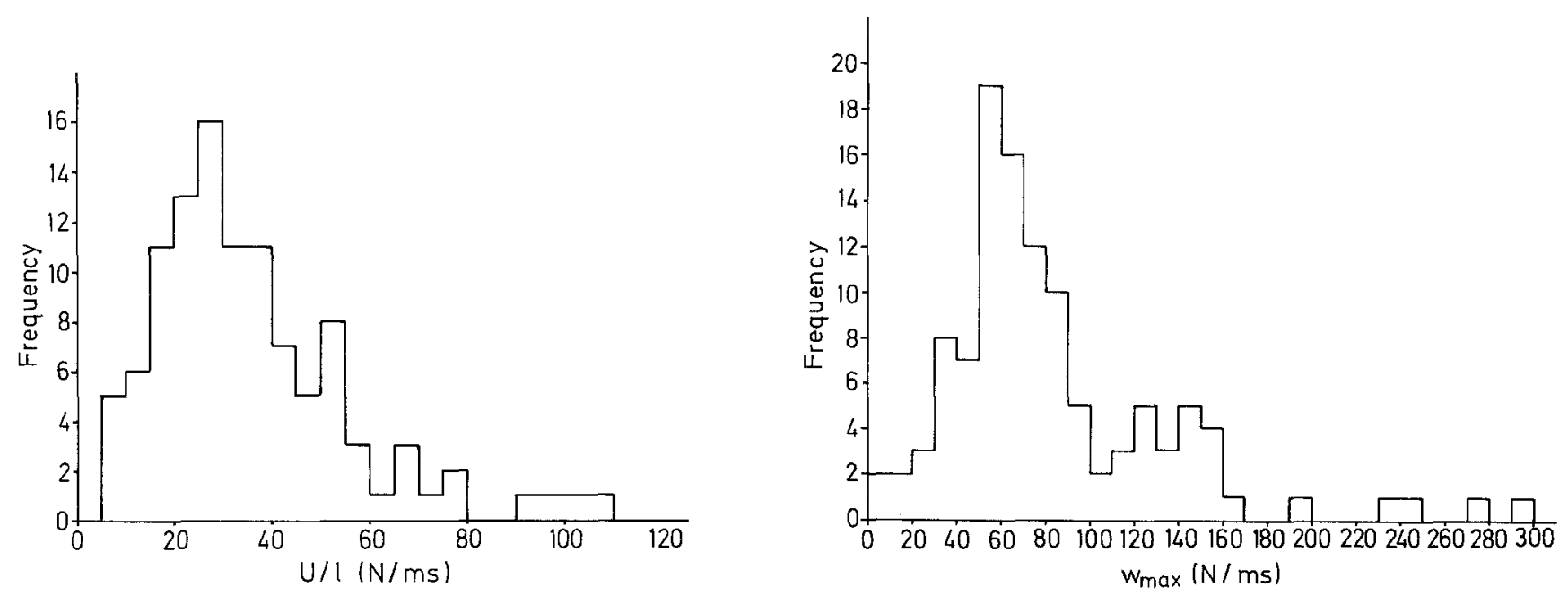

Fig. 6. Histogram of the parameter U/1 for the entire group of 218 measurements on 110 patients

Fig. 7. Histogram of the parameter $w_{\max }$ for the entire group of 218 measurements on 110 patients

As the parameter $w_{\max }$ is in essence a product of contraction velocity and pressure, a high $\mathrm{w}_{\max }$ value can mean either a high pressure or a high contraction velocity. The patients who had a high $\mathrm{w}_{\max }$ value were separated graphically into two groups, one where the influence of pressure was dominant, one where that of velocity was dominant, see Fig. 12. Differences between parameters were tested for significance by Student's t-test, correlations between parameters were calculated using Spearman's rank correlation coefficient. In order to estimate the effect of the filling catheter on the estimated parameters, especially in children, the parameters were correlated with the urethral opening pressure. This pressure was defined as the detrusor pressure at which a trigger level of $1 \mathrm{ml} / \mathrm{s}$ flow was exceeded.

\section{Results}

The group of 110 patients consisted of 34 patients with one successful measurement, 46 patients with two measurements, 29 patients with three measurements and 1 patient
Table 1. Averages and standard deviations of contractility parameters for the entire group of 218 measurements on 110 patients

\begin{tabular}{lll}
\hline parameter & $\mathrm{U} / 1$ & $\mathrm{w}_{\max }$ \\
\hline average & 37 & $89 \mathrm{~N} / \mathrm{ms}$ \\
standard deviation & 23 & $59 \mathrm{~N} / \mathrm{ms}$ \\
\hline
\end{tabular}

with five measurements. Figure 6 . shows a histogram of all 218 measured values of the parameter $\mathrm{U} / \mathrm{l}$, and Fig. 7. shows the $\mathrm{w}_{\text {max }}$ values. Table 1 contains the average values and standard deviations of both parameters. The median value of $\mathrm{U} / \mathrm{l}$ was found to be $33.5 \mathrm{~N} / \mathrm{ms}$ and this value was used to define patient groups with high (U/1 > $33.5 \mathrm{~N} / \mathrm{ms}$ ) and low $(\mathrm{U} / 1<33.5)$ bladder contractility. The median value of $\mathrm{w}_{\max }$ was $75 \mathrm{~N} / \mathrm{ms}$ and was used to define similar groups 


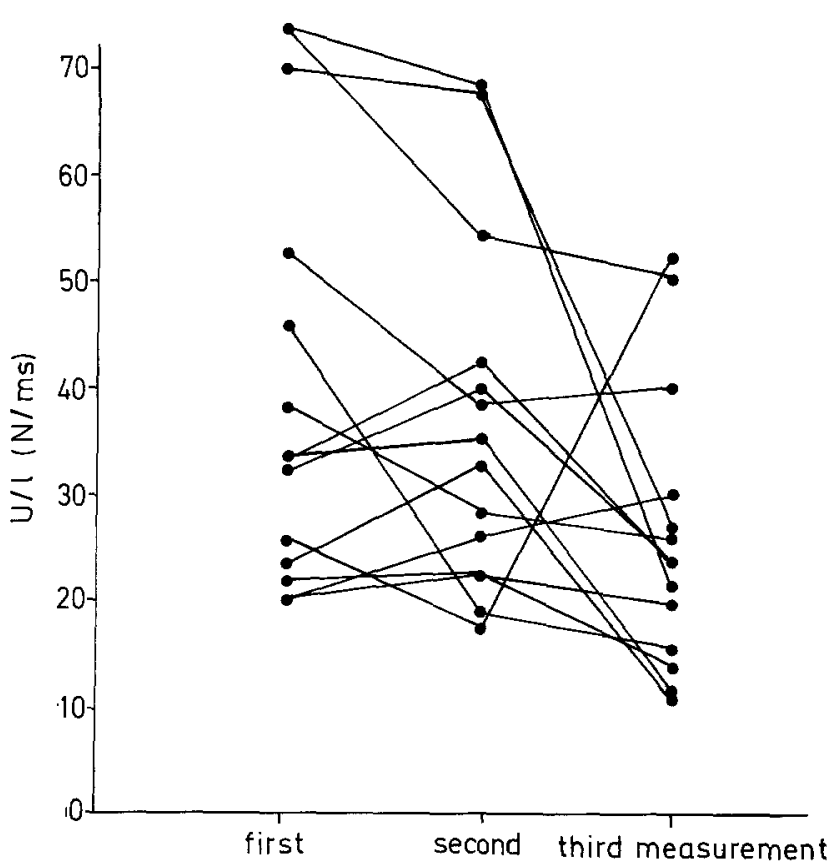

Fig. 8

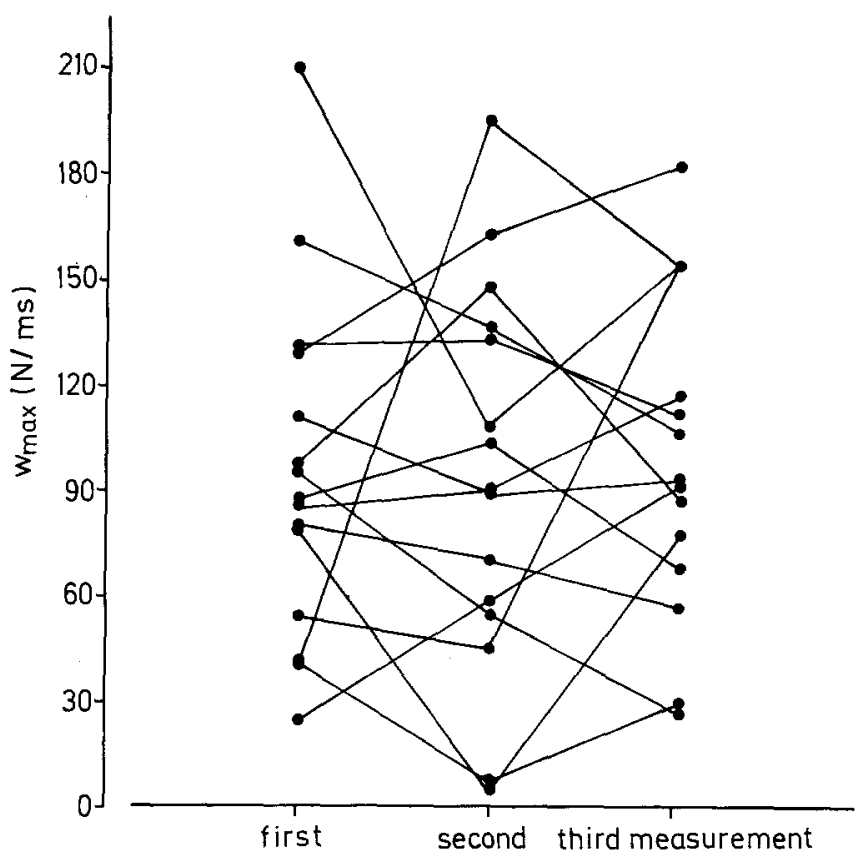

Fig. 9

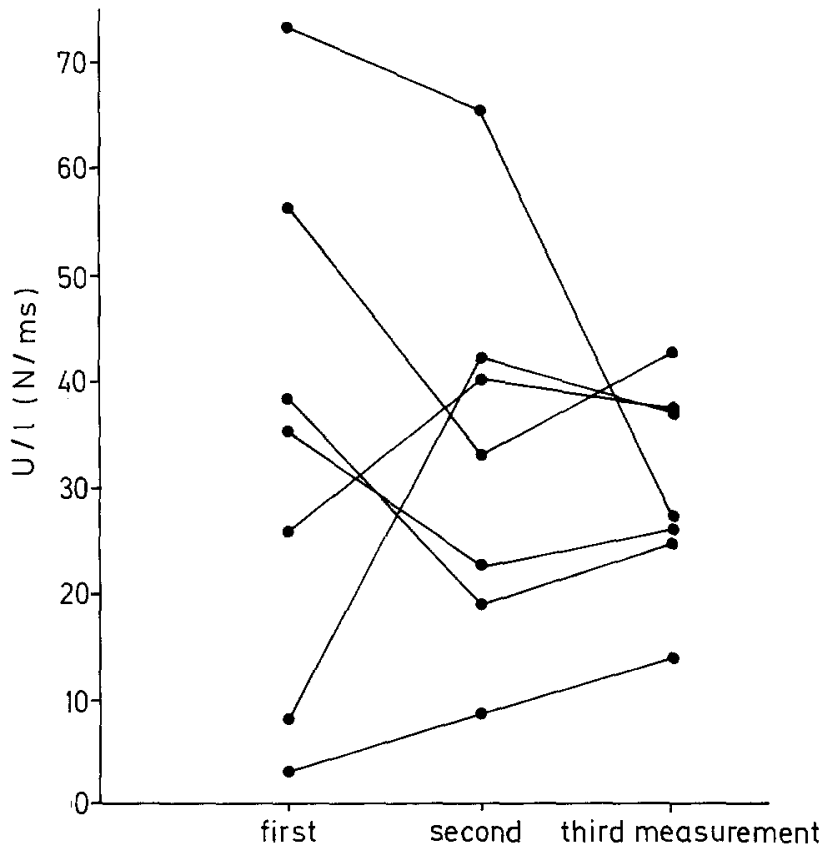

Fig. 10

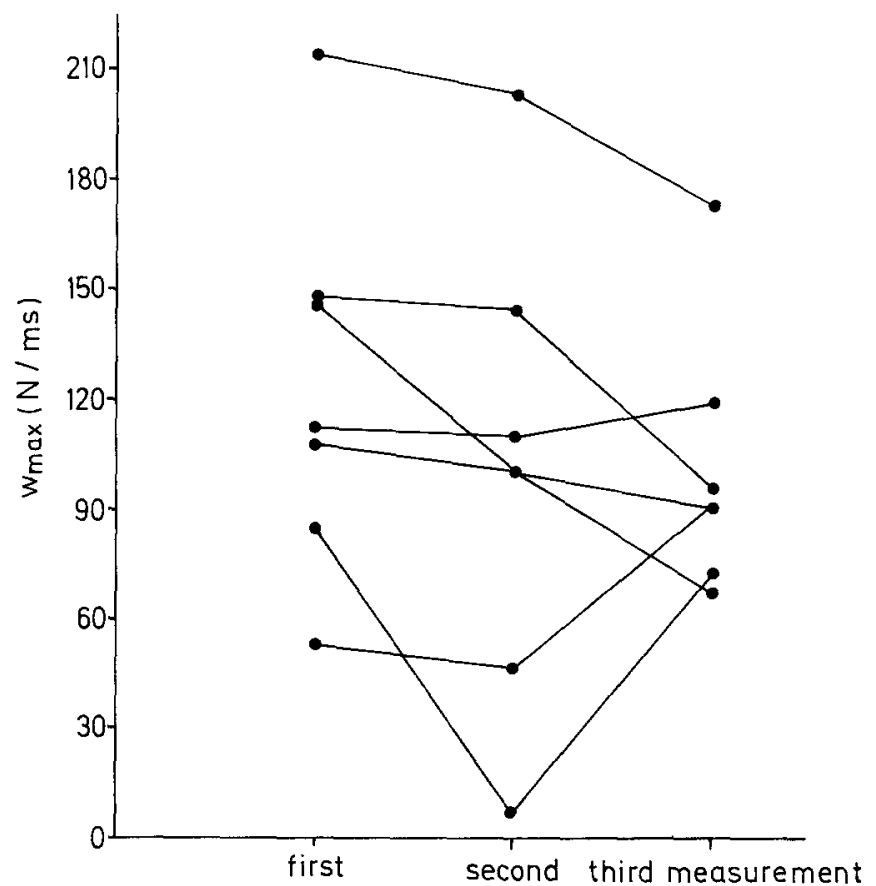

Fig. 11

Fig. 8. Reproducibility of the parameter $\mathrm{U} / 1$ for three successive measurements on 14 boys. Before the third measurement the $8 \mathrm{~F}$ filling catheter was removed

Fig. 9. Reproducibility of the parameter $\mathrm{w}_{\max }$ for three successive measurements on 15 boys. Before the third measurement the $8 \mathrm{~F}$ filling catheter was removed

Fig. 10. Reproducility of the parameter $U / 1$ for three successive measurements on 7 girls. Before the third measurement the $8 F$ filling catheter was removed

Fig. 11. Reproducility of the parameter $w_{\max }$ for three successive measurements on 7 girls. Before the third measurement the $8 \mathrm{~F}$ filling catheter was removed 
Table 2. Correlations between the parameters $U / 1$ and $\mathrm{w}_{\max }$ and the ureteral opening pressure for the group of boys with three successive measurements and for all patients. All shown (Spearman's rank) correlation coefficients are significant at the $1 \%$ level

\begin{tabular}{llc}
\hline $\begin{array}{l}\text { Correlation of urethral } \\
\text { opening pressure with }\end{array}$ & $\mathrm{U} / 1$ & $\mathrm{w}_{\max }$ \\
\hline 42 measurements (14 boys) & 0.73 & 0.35 \\
218 measurements (110 patients) & 0.77 & 0.36 \\
\hline
\end{tabular}

for this parameter. The reproducibility of the parameters was analysed in the children in whom three measurements were made. Figures 8 and 9 show respectively the three successive values of $U / 1$ and $w_{\max }$ measured in a group of 14 boys. Figures 10 and 11 show the same for a group of 7 girls. Notice that, in Fig. 8, the value of U/1 decrease from the first to the second measurement in 7 out of the 14 boys and increases in the other 7, indicating a non-systematic, random variation. From the second to the third measurements, U/1 decreases in 11 boys and increases in only 3 .
This indicates a systematically lower value of $U / 1$ in the third measurement, due to the fact that before the third measurement the filling catheter was removed. As can be seen in Fig. 10, this effect was not seen in girls. No effect on the parameter $w_{\max }$ was seen either in boys (Fig. 9) or in girls (Fig. 11). Table 2 shows the correlations between the parameters and urethral opening pressure for the group of boys with three successive measurements (Fig. 8 ) and for all measurements.

Table 3 shows averages and standard deviations of the parameter $\mathrm{U} / 1$, averaged per patient, and separately for boys, girls, adult men and women. There is a significant difference between the parameter values found for boys and girls, for boys and adult women, for adult men and girls, and for adult men and women. This means a significant difference between both sexes, regardless of age, males scoring a much higher $U / 1$ value. Table 4 shows averages and standard deviations of the parameter $\mathrm{w}_{\max }$ for the different groups. Here a significant difference was found between boys and adult men, between boys and adult women and between girls and adult men. Taking into consideration that the difference between girls and adult women just missed

Table 3. Averages and standard deviations of the parameter U/1, averaged for each patient ${ }^{\mathrm{a}}$. Values are shown for the entire group of patients, and for boys, girls, adult men and adult women separately. Significance of differences between the groups using Student's t-test

\begin{tabular}{|c|c|c|c|c|c|c|c|}
\hline \multirow[t]{2}{*}{ group } & \multirow[t]{2}{*}{ average } & \multirow[t]{2}{*}{ stder } & \multirow[t]{2}{*}{ units } & \multirow{2}{*}{$\begin{array}{l}\text { number } \\
\text { of }\end{array}$} & \multicolumn{3}{|c|}{ Difference with } \\
\hline & & & & & men & girls & women \\
\hline total & 36 & 20 & $\mathrm{~N} / \mathrm{ms}$ & 110 & & & \\
\hline boys & 47 & 24 & $\mathrm{~N} / \mathrm{ms}$ & 27 & $p<0.40$ & $p<0.0005$ & $p<0.0005$ \\
\hline men & 44 & 20 & $\mathrm{~N} / \mathrm{ms}$ & 20 & & $p<0.005$ & $p<0.005$ \\
\hline girls & 26 & 12 & $\mathrm{~N} / \mathrm{ms}$ & 22 & & & $p<0.25$ \\
\hline women & 30 & 15 & $\mathrm{~N} / \mathrm{ms}$ & 41 & & & \\
\hline
\end{tabular}

a The slight difference between the overall average value in this Table and the one in Table 1 is due to the fact that here the values were first averaged per patient, and next for all patients with equal weighting i.e. regardless whether one, two or three measurements were performed on each patient

Table 4. Averages and standard deviations of the parameter $w_{\max }$ averaged for each patient ${ }^{a}$. Values are shown for the entire group of patients, and for boys, girls, adult men and adult women separately. Significance of differences between the groups using Studen's t-test

\begin{tabular}{|c|c|c|c|c|c|c|c|}
\hline \multirow[t]{2}{*}{ group } & \multirow[t]{2}{*}{ average } & \multirow[t]{2}{*}{ stdev } & \multirow[t]{2}{*}{ units } & \multirow{2}{*}{$\begin{array}{l}\text { number } \\
\text { of }\end{array}$} & \multicolumn{3}{|c|}{ Difference with } \\
\hline & & & & & men & girls & women \\
\hline total & 84 & 52 & $\mathrm{~N} / \mathrm{ms}$ & 110 & & & \\
\hline boys & 102 & 53 & $\mathrm{~N} / \mathrm{ms}$ & 27 & $p<0.005$ & $p<0.40$ & $p<0.025$ \\
\hline men & 66 & 23 & $\mathrm{~N} / \mathrm{ms}$ & 20 & & $p<0.025$ & $p<0.40$ \\
\hline girls & 97 & 60 & $\mathrm{~N} / \mathrm{ms}$ & 22 & & & $p<0.10$ \\
\hline women & 73 & 51 & $\mathrm{~N} / \mathrm{ms}$ & 41 & & & \\
\hline
\end{tabular}

a The slight difference between the overall average value in this Table and the one in Table 1 is due to the fact that here the values were first averaged per patient, and next for all patients with equal weighting i.e. regardless whether one, two or three measurements were performed on each patient 
Table 5. Numbers of patients of each age and sex group in the categories defined by high and low values of the parameters $U / 1$ and $w_{m a x}$. Numbers are given absolute and as a percentage of the total number in each age/sex group. Average residual urine is given for each subgroup

\begin{tabular}{|c|c|c|c|c|c|c|}
\hline & \multicolumn{3}{|l|}{$\mathrm{U} / 1>$} & \multicolumn{3}{|l|}{$\mathrm{U} / 1<$} \\
\hline & & & $\operatorname{Res}(\mathrm{ml})$ & & & $\operatorname{Res}(\mathrm{ml})$ \\
\hline \multirow[t]{5}{*}{$\mathrm{w}_{\max }>$} & total & 26 & 30 & total & 21 & 36 \\
\hline & men & $3(15 \%)$ & 114 & men & $1(5 \%)$ & 1 \\
\hline & boys & $11(41 \%)$ & 21 & boys & $5(18 \%)$ & 58 \\
\hline & women & $7(17 \%)$ & 30 & women & $5(12 \%)$ & 19 \\
\hline & girls & $5(23 \%)$ & 1 & girls & $10(45 \%)$ & 38 \\
\hline \multirow[t]{5}{*}{$\mathrm{w}_{\max }<$} & total & 23 & 185 & total & 40 & 90 \\
\hline & men & $11(55 \%)$ & 187 & men & $5(25 \%)$ & 83 \\
\hline & boys & $5(19 \%)$ & 98 & boys & $6(22 \%)$ & 64 \\
\hline & women & $6(15 \%)$ & 284 & women & $23(56 \%)$ & 96 \\
\hline & girls & $1(5 \%)$ & 14 & girls & $6(27 \%)$ & 103 \\
\hline
\end{tabular}

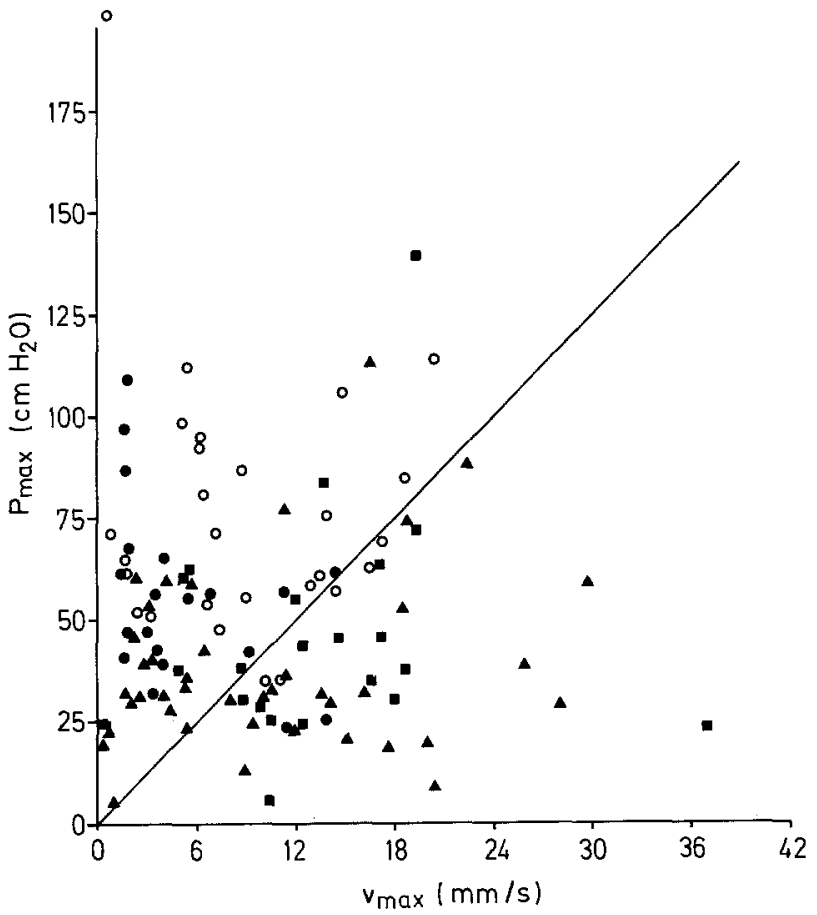

Fig. 12. Plot of maximum pressure attained during micturition as a function of maximum contraction velocity during micturition. Average of these parameters was presented as one point for each patient, open circles - boys, closed circles - men, triangles - girls, squares - women. Patients were divided into two groups using the shown straight line

significance at the $5 \%$ level, these differences can be summarized by stating that the $\mathrm{w}_{\max }$ parameter depends significantly on age, regardless of sex, children yielding a much higher $\mathrm{w}_{\max }$ value than adults. Finally Table 5 shows the numbers of patients in the subgroups defined by high and low values of the parameters $U / 1$ and $w_{\max }$. As might be expected on the basis of the significant dependence on age and sex shown in Tables 3 and 4, each of the four groups in Table 5 is dominated by patients in one age/sex group. The boys are predominantly present in the group with high $U / 1$ and high $\mathrm{w}_{\max }$ which is a group of patients with a consistently highly contractile bladder. The average residue for the 11 boys in this group is significantly smaller than the average residue for boys in the other parameter groups. Of the 11 boys, 10 suffered from enuresis nocturna, 9 had unstable bladders and 8 were definitely not obstructed. Thus this group consisted of boys with probably normal or overactive bladder. Separation into patients with dominant pressure or patients with dominant contraction velocity, using Fig. 12 showed that 9 out of the 11 boys scored a high $\mathrm{w}_{\max }$ value because of a high pressure during micturition.

The apparently conflicting group with high $\mathrm{w}_{\max }$ and low U/1 contains $45 \%$ of all girls in our patient material. of these 10 girls, 8 score a high $\mathrm{w}_{\max }$ due to a high contraction velocity. Pressure is not very important in this group, and consequenlty $\mathrm{U} / 1$ is not high. Since the average residue is not very high these girls void well in general, at a relatively low pressure. Nevertheless the average residue is definitely lower in the group with high $\mathrm{w}_{\max }$ and high $\mathrm{U} / \mathrm{l}$.

The other apparently conflicting group with low $\mathrm{w}_{\max }$ and high $\mathrm{U} / \mathrm{l}$ contains $55 \%$ of all adult males. Surprisingly we find the highest residue not only for the males, but for practically all age/sex groups, in this category and not in the category $\mathrm{U} / \mathrm{l}$ low, $\mathrm{w}_{\max }$ low. Of the 11 men in this category 2 were diagnosed as obstructed, 2 were doubtful cases, 4 had complaints indicating prostatism and 3 had had a TUR. Thus these patients are NOT just obstructed. A simple obstructed bladder, generating high pressure would cause a high $\mathrm{U} / 1$ and a high $\mathrm{w}_{\max }$. But here we find a good contractility before micturition and a failing voiding. This type of voiding is characterized by the fading away of the contraction before the bladder is empty. 

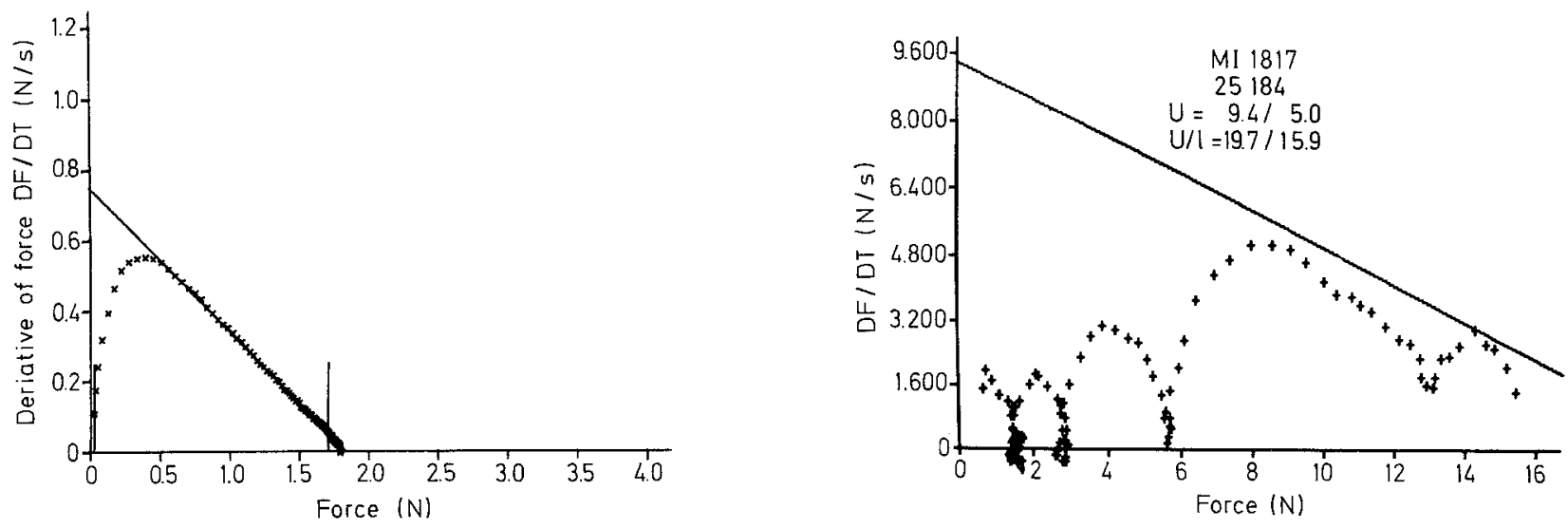

Fig. 13. Phase plot of iso metric contraction measured in vitro, showing the ideal, theoretical form of such a plot

Fig. 14. Phase plot of iso metric contraction of a patient, which shows loops due to the stepwise stimulation of the detrusor muscle

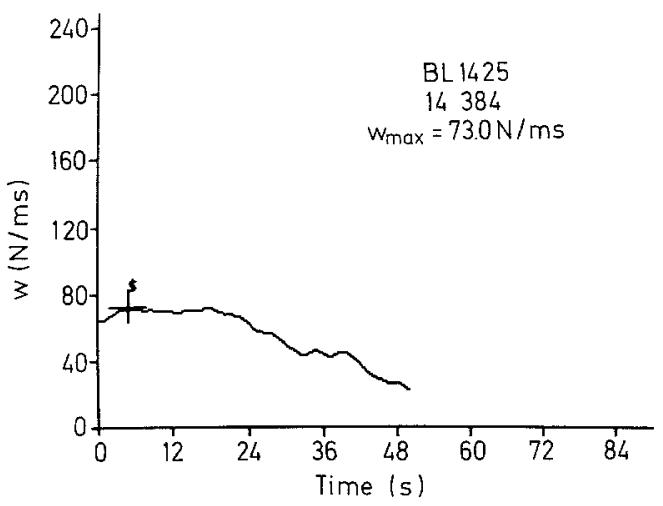

Fig. 15. Plot of the parameter $w$ as a function of time, where the bladder contraction fades away towards the end of micturition, leaving residual urine

Finally, the group with consistently low U/1 and low $\mathrm{w}_{\max }$ value contains $56 \%$ of the adult females. The majority of these ( 16 out of the 23) suffered from stress incontinence or pollakisuria. 10 patients had no residue at all in spite of the "low contractility" score. The other 13 patients definitely had a residue, but no obstruction. Nevertheless in the pressure-velocity comparison (Fig. 12) all 13 of these patients lie in the upper half of the plot, indicating dominance of pressure over contraction velocity.

\section{Discussion}

An ideal contractility parameter is a measure of the intrinsic mechanical properties of the bladder, and is not influenced by urethral properties, nor by neurogenic control. From the fact that the parameter $U / 1$ is significantly lower when the filling catheter is removed in boys, whereas this effect is not found in girls, it can be concluded that this parameter is severely influenced by urethral properties. In fact, the U/1 parameter is correlated very significantly with the opening pressure of the urethra (Table 2). Figure 13 shows a phase plot of an ideal isometric contraction in vitro. If in a real, clinical micturition contraction the uretra opens only when the straight line part of the phase plot is reached, so that up to the straight line part the contraction is isometric, reliable parameters can be obtained. If the urethra opens earlier, the determined $\mathrm{U} / 1$ parameter wil be related to the ure thral opening pressure, and not to bladder properties. As can be seen in Table 4 high values of $U / 1$ are also associated with higher values for residual urine. This apparent contradiction may be accounted for by the dependence of $U / 1$ on opening pressure, since infravesical obstruction may lead to both higher opening pressures (high $\mathrm{U} / 1$ values) and also to residual urine. Notice that an obstruction alone does not lead to a residual, since, if the bladder generates high pressures, there is no reason why emptying should not be complete [3]. Residual urine points to a failure of the bladder to maintain its contraction, probably as a result of changes in the bladder wall due to the obstruction. Figure 14 shows an example of a type of phase plot which was found frequently in our patient material, forming loops. This type of phaseplot may be interpreted in the following way: Patients tend not to fully "switch on" the bladder under normal circumstances but the neurogenic feedback and control system stimulates the bladder just enough to accomplish micturition. During these measurements, with ure thral catheters inserted, the ure thral resistance is higher than normal and therefore this "minimal stimulation" may be insufficient. Upon noticing this, the patient, or his neurogenic control system, raises the degree of stimulation, which results in a second loop in the phase plot. Summarizing, influences from the urethra as well as from the neurogenic control system are recongnizable in the $U / 1$ parameter, which is therefore far from an ideal contractility parameter. 
The parameter $\mathrm{w}_{\max }$ is the maximum of the variable $\mathrm{w}$ during the act of micturition. In the ideal case, changes in the urethra lead to a different balance between contraction velocity and pressure in the urinary bladder, i.e. to another working point on the force-velocity relation, but not to another $w$ value, since both variables are represented in $w$ in such a way that one force-velocity relation leads to one $w$ value. However, a w (max) value does not uniquely define a force-velocity relation, so that bladders with different force-velocity relations (and thus different contractility) might yield the same $w_{\max }$. Furthermore, $\mathrm{w}_{\max }$ approximates the maximum power per surface area actually generated by the bladder during a given micturition and not the maximum power it could generate. The correlation of $\mathrm{w}_{\max }$ and urethral opening pressure is just significant, but the correlation coefficient is not very high. Therefore, the variable $\mathrm{w}$ and its maximum the parameter $\mathrm{w}_{\max }$ are not influenced grossly by urethral properties. This can also be concluded from Fig. 9, where removal of the $8 \mathrm{~F}$ filling catheter in boys does not change $\mathrm{w}_{\mathrm{m} \text { ax }}$ significantly. The value of $w$ throughout micturition varies, probably as a result of a variation in the degree of neurogenic stimulation or as a result of geometric changes. In a normal micturition $w$ tends to increase slightly towards the end, as shown in Fig. 5. In some patients, $w$ decreases towards the end of micturition, leaving residual urine, as shown in Fig. 15. In both cases $\mathrm{w}_{\max }$ can have approximately the same value, (as in Figs. 5 and 15) one value lying at the end of micturition, the other at the beginning. Therefore $\mathrm{w}_{\max }$ does not always indicate this type of failure, whether myogenic or neurogenic in origin. Nevertheless a positive correlation exists between $\mathrm{w}_{\max }$ and the volume of residual urine, as can be seen from Table 5. High $\mathrm{w}_{\max }$ values are associated with low residual urine, and thus good bladder emptying. Summarizing, the $\mathrm{w}_{\max }$ parameter is not very sensitive to urethral changes, may be influenced by neurogenic control, does not necessarily recognize "fading away" of the detrusor contraction during micturition and reflects more the actual emptying of the bladder than the intrinsic properties of the detrusor muscle.

We must therefore conclude that neither $\mathrm{U} / \mathrm{l}$, nor $\mathrm{w}_{\max }$ are ideal contractility parameters. Each measures a characteristic of the detrusor which is related to contractility, but does not conform to the definition of contractility in a strict sense. If both parameters are used an apparent contradiction is found in about $40 \%$ of patients $(21+23$ out of the 110 ), which can be understood by realizing that both parameters measure different properties, or different approximations of contractility. If only one parameter is used, $\mathrm{w}_{\max }$ must be preferred as it is less influenced by urethral properties.

\section{References}

1. Griffiths DJ (1977) Urodynamic assessment of bladder function. Br J Urol 49:29-36

2. Griffiths DJ, Scholtmeijer RJ (1982) Precise urodynamic assessment of anatomic urethral obstruction in boys. Neurourol Urodyn 1:97-104

3. Griffiths DJ (1982) The mechanism of micturition. In: Chisholm GD, Innes Williams D (eds) Scientific foundations of Urology.'Heinnemann Medical Books, London, pp 419-420

4. Griffiths DJ, van Mastrigt R (1985) The routine assessment of detrusor contraction strength. Neurourol Urodyn 4:77-87

5. van Mastrigt $R$, Griffiths DJ (1979) Contractility of the urinary bladder. Urol Int 34:410-420

6. van Mastrigt $R$, van Duyl WA (1982) Mechanics of detrusor contraction. Determination of contractility. In: Principles of bladder function and urodynamics. Utrecht, pp 31-36

7. van Mastrigt $R$, Thon $H R$, van de Giessen $H$ (1983) Analog data collection via a telephone line. A microprocessor-based remote-controlled data-acquisition system. Med Biol Eng Comput 21-2:229-231

8. van Mastrigt $R$ (1983) Determination of the contractility of children's bladders from isometric contractions. Urol Int 38-6:354-362

9. van Mastrigt $R$ (1983) A comparison of contractility parameters determined from pressure-flow studies and isometric contractions. Proc 2nd joint meeting ICS-UDS, Aachen, pp 41-43

10. van Mastrigt $R$, Glerum JJ (1985) In vitro comparison of isometric and stop-test contractility parameters for the urinary bladder. Urol Res 13:11-17

11. van Mastrigt $R$, Griffiths DJ (1984) A clinical comparison of contractility parameters determineed from isometric contractions and pressure-flow studies of the urinary bladder. J Urol 131/4-2:190A

12. van Mastrigt $R$ (1984) A computer program for on-line measurement, storage, analysis and retrieval of urodynamic data. Comput Programs Biomed 18:109-117

13. can Mastrigt $R$ (1984) Computer programs for urodynamics. Neurol Urodyn 3-2:141-142

14. van Mastrigt R, Griffiths DJ (1984) Classification of the contractility of the urinary bladder. Proc XIVth ICS meeting, Innsbruck, pp 188-190

15. van Mastrigt $R$, Glerum JJ (1985) Electrical stimulation of smooth muscle strips from the urinary bladder of the pig. $J$ Biomed Eng 7-1:2-8

16. van Mastrigt R, Griffiths DJ (1985) A clinical comparison of bladder contractility parameters calculated from isometric contractions and pressure-flow studies. Urology (accepted)

17. Siroky MB, Krane RJ (1983) A method for clinical assessment of detrusor muscle mechanics Proc. 2nd joint meeting ICS-UDS, Aachen, pp 29-31

R. van Mastrigt

Dept. of Urology

Erasmus University Rotterdam

Room EE1630

PO Box 1738

3000 DR Rotterdam

The Netherlands 